\title{
Patient-Reported Symptom Severity, Interference With Daily Activities, and Adverse Events in Older and Younger Women Receiving Chemotherapy for Early Breast Cancer
}

\author{
Kirsten A. Nyrop, PhD (iD 1,2; Allison M. Deal, MS²; Yi Tang Chen, BA 3; Bryce B. Reeve, PhD (iD) 4; Ethan M. Basch, MD (iD) 1,2; \\ William A. Wood, MD ${ }^{1,2}$; Shlomit S. Shachar, MD ${ }^{5}$; Lisa A. Carey, MD ${ }^{1,2}$; Katherine E. Reeder-Hayes, MD (iD 1,2; \\ E. Claire Dees, MD 1,2; Trevor A. Jolly, MBBS ${ }^{1,2}$; Gretchen G. Kimmick, MD, MS ${ }^{4}$; Meghan S. Karuturi, MD (iD 6; Raquel E. \\ Reinbolt, MD (ID 7; JoEllen C. Speca, MD'; Jordan T. Lee, MA (iD 8; Addison Brenizer, BA 2 ; and Hyman B. Muss, MD ${ }^{1,2}$
}

\begin{abstract}
BACKGROUND: To the authors' knowledge, it is unknown whether patient-reported symptom severity and symptom interference with daily activities differ between younger (aged $<65$ years) and older (aged $\geq 65$ years) women receiving similar chemotherapy regimens for early breast cancer (EBC). METHODS: Study participants rated 17 side effects of chemotherapy regimens currently in use in clinical practice (2014-2019). RESULTS: Of 284 women with EBC (stage I-III), approximately 57\% were aged $<65$ years and $43 \%$ were aged $\geq 65$ years. For anthracycline-based regimens, a higher percentage of younger women reported moderate, severe, or very severe (MSVS) hot flashes $(49 \%$ vs $18 \%)(P<.001)$. For nonanthracycline regimens, a higher percentage of younger women reported MSVS hot flashes (38\% vs 19\%) $(P=.009)$ and a lower percentage reported MSVS arthralgia ( $28 \%$ vs $49 \%)(P=.005)$. With regard to symptom interference with daily activities, a higher percentage of younger women being treated with anthracycline-based regimens reported MSVS hot flashes ( $32 \%$ vs $7 \%)(P=.001)$ and myalgia (38\% vs $18 \%)(P=.02)$. For nonanthracycline chemotherapy, a higher percentage of younger women reported MSVS interference for hot flashes (26\% vs $9 \%)(P=.006)$ and lower percentages reported abdominal pain ( $13 \%$ vs $28 \%$ ) $(P=.02)$. Overall, there were no significant differences noted among younger versus older patients with regard to hospitalizations (19\% vs $12 \% ; P=.19$ ), dose reductions ( $34 \%$ vs $31 \% ; P=.50$ ), dose delays ( $22 \%$ vs $25 \%$; $P=.59$ ), or early treatment discontinuation ( $16 \%$ vs $16 \%$; $P=.9546)$. CONCLUSIONS: Older and younger women with EBC who were treated with identical chemotherapy regimens generally experienced similar levels of symptom severity, symptom-related interference with daily activities, and adverse events. Cancer 2021;127:957-967. (c) 2020 American Cancer Society.
\end{abstract}

\section{LAY SUMMARY:}

- In the current study, women receiving chemotherapy for early breast cancer rated the severity of 17 symptoms and symptom interference with their activities of daily living.

- Older (aged $\geq 65$ years) and younger (aged $<65$ years) women who received identical chemotherapy regimens generally experienced similar levels of symptom severity, symptom-related interference with daily activities, and adverse events.

KEYWORDS: breast cancer, chemotherapy, interference, severity, side effects.

\section{INTRODUCTION}

Breast cancer is largely a disease of aging, with the incidence of new cases rising with age. ${ }^{1}$ Early detection and improved adjuvant therapies have resulted in steady improvements in survival rates, ${ }^{1}$ with newer chemotherapies and radiotherapy being important components of these treatment advances. Women with early breast cancer who are aged $\geq 65$ years remain underrepresented in treatment trials. ${ }^{2,3}$ However, clinician-graded toxicity scores (the National Cancer Institute's Common Terminology Criteria for Adverse Events [CTCAE] $)^{4,5}$ obtained from treatment trials have shown that older women can both tolerate and benefit from newer treatments. ${ }^{6-8}$ These findings suggest that age alone should not be the sole criterion for decisions regarding chemotherapy. Instead, treatment options should be based on an assessment of the patient's physical reserves as well as the patient's goals, life expectancy, and tumor biology. ${ }^{9} 11$

Patient-reported symptom monitoring during treatment has emerged as an important complement to clinician-assessed toxicity, both in clinical trials ${ }^{12,13}$ as well as in clinical practice. ${ }^{14-16}$ We previously observed that

Corresponding Author: Kirsten A. Nyrop, PhD, Division of Hematology-Oncology, School of Medicine, University of North Carolina at Chapel Hill, 170 Manning Dr, Campus Box 7305, Chapel Hill, NC 27599-7305 (kirsten_nyrop@med.unc.edu).

${ }^{1}$ School of Medicine, University of North Carolina at Chapel Hill, Chapel Hill, North Carolina; ${ }^{2}$ Lineberger Comprehensive Cancer Center, University of North Carolina at Chapel Hill, Chapel Hill, North Carolina; ${ }^{3}$ Gillings School of Global Public Health, University of North Carolina at Chapel Hill, Chapel Hill, North Carolina; ${ }^{4}$ Duke University School of Medicine, Durham, North Carolina; ${ }^{5}$ Rambam Health Campus, Haifa, Israel; ${ }^{6}$ The University of Texas MD Anderson Cancer Center, Houston, Texas; ${ }^{7}$ Ohio State University Comprehensive Cancer Center, Columbus, Ohio; ${ }^{8}$ Department of Exercise and Sport Science, University of North Carolina at Chapel Hill, Chapel Hill, North Carolina

Additional supporting information may be found in the online version of this article.

DOI: 10.1002/cncr.33329, Received: August 24, 2020; Revised: October 1, 2020; Accepted: October 23, 2020, Published online November 20, 2020 in Wiley Online Library (wileyonlinelibrary.com) 
patient-reported symptom severity varies significantly among 4 chemotherapy regimens commonly used in current clinical practice for the treatment of early breast cancer, and that patients receiving anthracycline-based regimens had significantly higher rates of moderate, severe, or very severe (MSVS) symptoms compared with patients receiving regimens that were not anthracycline based. ${ }^{17}$ In this sample of patients, we also observed that clinicians often underestimate the severity of chemotherapy side effects compared with patient reports of symptom severity. ${ }^{18}$

Clinician concerns regarding an increased risk of toxicity in older patients who are receiving adjuvant chemotherapy can result in undertreatment and may, in part, explain the poorer breast cancer-specific survival noted in older women with early-stage breast cancer. ${ }^{19}$ In the current study, we investigated whether patient-reported symptom severity differs between younger women (those aged $<65$ years) and older women (those aged $\geq 65$ years) receiving similar chemotherapy regimens. We chose age 65 years because this is the cut point commonly used to define the "older" patient, most likely relating to the age for receiving Medicare. We also investigated symptom "interference with activities of daily living," which to our knowledge is a seldom-reported side effect. The current study data included 17 symptoms monitored prospectively throughout chemotherapy. We also compared hospitalizations and treatment changes (dose reduction, early treatment discontinuation). The objective of the current study was to further our understanding of chemotherapy treatment tolerability in older compared with younger women with early breast cancer.

\section{MATERIALS AND METHODS}

\section{Study Participants}

The current study was an ancillary analysis of data from 3 studies investigating self-directed walking during chemotherapy for early breast cancer. The studies were approved by the University of North Carolina at Chapel Hill (UNC) Lineberger Comprehensive Cancer Center protocol review committee and the UNC institutional review board. The trial is registered at ClinicalTrials.gov (ClinicalTrials.gov identifier NCT02328313) and is a multisite study with institutional review board approval at participating sites (UNC, Duke University Medical Center, The University of Texas MD Anderson Cancer Center, and the Ohio State University Comprehensive Cancer Center). The enrollment period was from March
2014 to December 2019. The protocols were identical with the exception of varying age criteria: women aged 21 to 64 years at the time of breast cancer diagnosis (ClinicalTrials.gov identifier NCT02167932), women aged $\geq 65$ years at the time of breast cancer diagnosis (ClinicalTrials.gov identifier NCT02328313), and women aged $\geq 21$ at the time of breast cancer diagnosis (ClinicalTrials.gov identifier NCT03761706). For all 3 studies, women with histologically confirmed state I to stage III breast cancer ${ }^{20}$ who were scheduled to receive (neo)adjuvant chemotherapy were approached in the clinic, confirmed for eligibility (clinician consent to engage in moderate walking), and invited to participate by providing written informed consent meeting all federal, state, and institutional guidelines. Further details regarding the patient population have been published previously. ${ }^{17,18,21}$

\section{Chemotherapy Regimens}

Chemotherapy regimens were administered at the discretion of the treating oncologist in consultation with the patient, depending on the breast cancer stage ${ }^{22}$ and phenotype. For the current study, there was no a priori selection of patients receiving specific chemotherapy regimens. Four regimens accounted for approximately $81 \%$ of all regimens in the primary studies: 1) dosedense doxorubicin and cyclophosphamide followed by paclitaxel (AC-T) (30\% of patients); 2) docetaxel and cyclophosphamide (TC) (27\% of patients); 3) docetaxel and carboplatin with anti-HER2 therapy (TCH) (16\% of patients); and 4) doxorubicin and cyclophosphamide plus paclitaxel and carboplatin (AC-TC) $(7 \%$ of patients).

\section{Measures}

\section{Chemotherapy side effects}

At infusion visits throughout chemotherapy, patients rated 17 symptoms using a patient-reported symptom monitoring form: fatigue, insomnia, anxiety, depression, dyspnea, peripheral neuropathy, joint pain and/or arthralgia, muscle pain and/or myalgia, abdominal pain, general pain, edema of the extremities, constipation, diarrhea, nausea, vomiting, mucositis, and hot flashes. For patients with infusion schedules every 2 or 3 weeks, symptom reports were collected at the time of each visit; for patients with weekly infusion schedules, symptom reports were collected every 2 weeks. The day of infusion was used for data collection to standardize the time frame ("past 7 days") across all 17 symptoms and all regimens and to reduce the burden on study participants. 
For 2 studies (ClinicalTrials.gov identifiers NCT02167932 and NCT02328313), symptoms were collected using a patient-tested measure called PatientReported Symptom Monitoring (PRSM). ${ }^{13}$ The PRSM studies predated the widespread availability of the PatientReported Outcomes-CTCAE (PRO-CTCAE), ${ }^{23,24}$ which was used in the third study (ClinicalTrials.gov identifier NCT03761706) when it became available to the general community. The phrasing to elicit symptom severity (intensity and/or frequency) and symptom interference with daily activities ("keep you from doing things you usually do") over the past 7 days was similar between the PRSM and PRO-CTCAE (see Supporting Information A for PRSM and Supporting Information B for PRO-CTCAE). Response options were on a 5-point Likert-type scale from 1 (least) to 5 (worst). The maximum rating of $1,2,3,4$, or 5 was recorded for each symptom per patient. This approach to side effects assessment is analogous to CTCAE reporting in clinical trials, in which the maximum toxicity grade at any time during chemotherapy is reported. Our specific interest was the percentage of patients who rated individual symptoms as "moderate," "severe," or "very severe" (MSVS) at any time during chemotherapy.

\section{Demographics, breast cancer diagnosis, treatment, and adverse events}

Age, race, educational level, marital status, living arrangements, and employment status were reported by study participants using a pretreatment questionnaire. Research staff reviewed the electronic medical record (EPIC Systems, Verona, Wisconsin) for data pertaining to breast cancer diagnosis and treatment and body mass index. Staff also collected data from the electronic medical record regarding chemotherapy-related adverse events such as hospitalizations, dose delays, dose reductions, and treatment discontinuations. Any hospitalizations outside Epic@UNC (including outside Care Everywhere) were not captured.

\section{Statistical Analysis}

Descriptive statistics are reported for all measures. Chisquare tests, Fisher exact tests, and Student $t$ tests were used to compare differences in patient characteristics, breast cancer diagnosis and treatment, patient-reported chemotherapy toxicities, and chemotherapy adverse events between older and younger patients. Statistical significance was set at $P=.05$. All analyses were conducted using SAS statistical software (SAS Institute Inc, Cary, North Carolina).

\section{RESULTS}

\section{Patient Characteristics}

Table 1 provides an overview of patient characteristics, comparing 163 patients aged $<65$ years with 121 patients aged $\geq 65$ years. With regard to chemotherapy use, a higher percentage of younger patients received neoadjuvant chemotherapy $(P=.007)$ and an anthracycline-based regimen $(P=.021)$. Specific chemotherapy regimens varied by age between younger versus older patients $(P<.001)$ : AC-T: $36 \%$ versus $25 \%$; AC-TC: $11 \%$ versus $3 \%$; TC: $25 \%$ versus $28 \%$; TCH: $20 \%$ versus $12 \%$; and other: $10 \%$ versus $31 \%$. There were no significant differences with regard to the mean number of symptom reports collected from younger versus older patients noted by regimen: AC-T: 8 reports versus 9 reports $(P=.92)$; AC-TC: 13 reports versus 13 reports $(P=.67)$; TC: 4 reports versus 4 reports $(P=.17)$; and TCH: 6 reports versus 6 reports $(P=.52)$.

\section{Symptom "Severity"}

To account for the type of chemotherapy regimen administered, we separately analyzed anthracycline-based and non-anthracycline-based regimens for the percentage of symptoms rated as MSVS by younger versus older patients (Table 2). Among patients receiving anthracycline-based regimens (Fig. 1), a higher percentage of younger women reported MSVS hot flashes (49\% vs $18 \%)(P<.001)$. Among women not receiving anthracycline-based regimens (Fig. 2), a higher percentage of younger women reported MSVS hot flashes (38\% vs $19 \%)(P=.009)$ and a lower percentage reported MSVS arthralgia $(28 \%$ vs $49 \%)(P=.005)$. For all other symptoms, there were no significant differences in symptom severity scores observed between the age groups.

In Supporting Table 1, symptom severity in younger versus older patients is compared for the 4 most common chemotherapy regimens: AC-T, AC-TC, $\mathrm{TC}$, and TCH. Again, there were minimal differences in symptom severity noted between the 2 age groups. A higher percentage of younger women reported MSVS hot flashes during treatment with AC-T (50\% vs $23 \%$; $P=.01)$ and TCH (39\% vs $7 \% ; P=.04)$, and a higher percentage reported MSVS constipation during treatment with AC-TC $(78 \%$ vs $0 \% ; P<.01)$. During treatment with TC, higher percentages of older women reported MSVS arthralgia ( $25 \%$ vs $50 \%$; $P=.03$ ), myalgia (23\% vs $47 \% ; P=.03$ ), and nausea ( $8 \%$ vs $29 \%$; $P=.02)$. 
TABLE 1. Patient Characteristics

\begin{tabular}{|c|c|c|c|c|}
\hline Variable & Overall $\mathrm{N}=284$ & Age $<65$ Years $N=163$ & Aged $\geq 65$ Years $N=121$ & $P^{\mathrm{a}}$ \\
\hline Age, y & $57(\mathrm{SD}, 12.9)$ & $48(S D, 9.2)$ & $70(\mathrm{SD}, 4.4)$ & $<.001$ \\
\hline \multicolumn{5}{|l|}{ Race } \\
\hline White & 208 (73\%) & $112(68 \%)$ & 96 (79\%) & \multirow[t]{3}{*}{.12} \\
\hline Black & $61(22 \%)$ & $40(25 \%)$ & $21(17 \%)$ & \\
\hline Other & $15(5 \%)$ & $12(7 \%)$ & $4(3 \%)$ & \\
\hline \multicolumn{5}{|l|}{ Educational level } \\
\hline$\leq$ High school & 40 (14\%) & $19(12 \%)$ & $21(18 \%)$ & \multirow[t]{2}{*}{.18} \\
\hline >High school & $241(86 \%)$ & $142(88 \%)$ & $99(83 \%)$ & \\
\hline \multicolumn{5}{|l|}{ Breast cancer stage ${ }^{20}$} \\
\hline 1 & 67 (24\%) & 31 (19\%) & $36(30 \%)$ & \multirow[t]{3}{*}{.07} \\
\hline ॥ & $145(51 \%)$ & 85 (52\%) & $60(50 \%)$ & \\
\hline III & $72(25 \%)$ & $47(29 \%)$ & $25(21 \%)$ & \\
\hline HER2 positive & 73 (26\%) & $43(26 \%)$ & 30 (25\%) & .76 \\
\hline HR positive & $90(60 \%)$ & $17(57 \%)$ & $73(60 \%)$ & .71 \\
\hline \multicolumn{5}{|l|}{$\begin{array}{l}\text { Breast cancer } \\
\text { phenotype }\end{array}$} \\
\hline HR+/HER2- & $129(45 \%)$ & $74(45 \%)$ & 55 (45\%) & \multirow[t]{4}{*}{.60} \\
\hline HR-/HER2- & $82(29 \%)$ & $46(28 \%)$ & 36 (30\%) & \\
\hline HR+/HER2+ & $38(13 \%)$ & $23(14 \%)$ & $18(15 \%)$ & \\
\hline HR-/HER2+ & $35(12 \%)$ & $23(14 \%)$ & $12(10 \%)$ & \\
\hline Radiation & $196(73 \%)$ & $118(74 \%)$ & $78(72 \%)$ & .72 \\
\hline \multicolumn{5}{|l|}{ Chemotherapy timing } \\
\hline Neoadjuvant & $110(39 \%)$ & 75 (46\%) & 35 (29\%) & \multirow{2}{*}{.007} \\
\hline Adjuvant & $172(61 \%)$ & 86 (53\%) & 86 (71\%) & \\
\hline \multicolumn{5}{|l|}{$\begin{array}{l}\text { Chemotherapy } \\
\text { regimens/drug } \\
\text { combinations }\end{array}$} \\
\hline AC-T & $90(32 \%)$ & 59 (36\%) & $31(25 \%)$ & \multirow[t]{5}{*}{$<.001$} \\
\hline $\begin{array}{l}\text { AC-TC plus anti- } \\
\text { HER2 therapy }\end{array}$ & $22(8 \%)$ & $18(11 \%)$ & $4(3 \%)$ & \\
\hline $\begin{array}{l}\mathrm{TC} \pm \text { anti-HER2 } \\
\text { therapy }\end{array}$ & 74 (26\%) & $40(25 \%)$ & $34(28 \%)$ & \\
\hline $\mathrm{TCH}$ & 47 (17\%) & $33(20 \%)$ & $14(12 \%)$ & \\
\hline Other & 59 (19\%) & $18(10 \%)$ & $41(31 \%)$ & \\
\hline $\begin{array}{l}\text { Duration of chemo- } \\
\text { therapy }>3 \mathrm{mo}\end{array}$ & 100 (67\%) & $62(70 \%)$ & $38(63 \%)$ & $<.001$ \\
\hline \multicolumn{5}{|l|}{$\begin{array}{l}\text { Chemotherapy } \\
\text { regimen }\end{array}$} \\
\hline $\begin{array}{l}\text { Non-anthracycline- } \\
\text { based }\end{array}$ & $156(55 \%)$ & $80(49 \%)$ & $76(63 \%)$ & \multirow[t]{2}{*}{.021} \\
\hline Anthracycline-based & $128(45 \%)$ & $83(51 \%)$ & 45 (37\%) & \\
\hline \multicolumn{5}{|l|}{ Hospitalization } \\
\hline Yes & $47(17 \%)$ & $31(19 \%)$ & $17(12 \%)$ & \multirow[t]{2}{*}{.19} \\
\hline No & $236(83 \%)$ & $131(81 \%)$ & $103(73 \%)$ & \\
\hline \multicolumn{5}{|l|}{ Dose reduction } \\
\hline Yes & $93(33 \%)$ & $56(34 \%)$ & 37 (31\%) & \multirow[t]{2}{*}{.50} \\
\hline No & $191(67 \%)$ & 107 (66\%) & 84 (69\%) & \\
\hline \multicolumn{5}{|l|}{ Dose delay } \\
\hline Yes & $66(23 \%)$ & $36(22 \%)$ & $30(25 \%)$ & \multirow[t]{2}{*}{.59} \\
\hline No & $218(77 \%)$ & $127(78 \%)$ & 91 (75\%) & \\
\hline \multicolumn{5}{|l|}{$\begin{array}{l}\text { Early treatment } \\
\text { discontinuation }\end{array}$} \\
\hline Yes & 45 (16\%) & $26(16 \%)$ & $19(16 \%)$ & \multirow[t]{2}{*}{.95} \\
\hline No & $239(84 \%)$ & $137(84 \%)$ & $102(84 \%)$ & \\
\hline
\end{tabular}

Abbreviations: -, negative; +, positive; AC-T, dose-dense doxorubicin and cyclophosphamide followed by paclitaxel; AC-TC, doxorubicin and cyclophosphamide plus paclitaxel and carboplatin; HR, hormone receptor; TC, docetaxel and cyclophosphamide; TCH, docetaxel and carboplatin with anti-HER2 therapy.

äBold type indicates statistical significance.

\section{Symptom Interference With Daily Activities}

Figures 1 and 2 illustrate the percentage of patients reporting MSVS symptom interference with activities of daily living. Overall, both younger and older patients reported that symptom interference was lower than symptom severity. Among patients receiving anthracycline-based chemotherapy regimens (Fig. 1) (Table 3), a higher percentage of younger women reported MSVS interference associated with hot flashes (32\% vs 7\%; $P=.001)$ and myalgia $(38 \%$ vs $18 \% ; P=.02)$. Among women not receiving anthracycline-based regimens (Fig. 2) (Table 3), a higher percentage of younger women reported MSVS 
TABLE 2. Patient-Reported Symptom Severity (MSVS) of Anthracycline-Based and Nonanthracycline Chemotherapy Regimens in Younger Versus Older Patients (Shown as the Percentage)

\begin{tabular}{|c|c|c|c|c|}
\hline Symptom & $\begin{array}{l}\text { Anthracycline-Based } \\
\text { (AC-T and AC-TC) }\end{array}$ & $P^{\mathrm{a}}$ & $\begin{array}{c}\text { Nonanthracycline-Based } \\
\text { (TC and TCH) }\end{array}$ & $P^{\mathrm{a}}$ \\
\hline \multicolumn{5}{|c|}{ Mean total no. of symptoms rated MSVS } \\
\hline Age $<65$ y & $6.9 \pm 4.0$ & \multirow[t]{2}{*}{.21} & $5.4 \pm 4.1$ & \multirow[t]{2}{*}{.25} \\
\hline Age $\geq 65$ y & $6.0 \pm 3.5$ & & $6.2 \pm 3.7$ & \\
\hline \multicolumn{5}{|c|}{ Fatigue, lack of energy } \\
\hline Age $<65$ y & 63 (77\%) & \multirow[t]{2}{*}{.34} & 49 (61\%) & \multirow[t]{2}{*}{.16} \\
\hline Age $\geq 65 y$ & 37 (84\%) & & $54(72 \%)$ & \\
\hline \multicolumn{5}{|l|}{ Anxiety } \\
\hline Age $<65$ y & $38(46 \%)$ & \multirow[t]{2}{*}{.49} & $32(40 \%)$ & \multirow[t]{2}{*}{.61} \\
\hline Age $\geq 65$ y & $23(51 \%)$ & & $33(44 \%)$ & \\
\hline \multicolumn{5}{|l|}{ Depression } \\
\hline Age $<65$ y & 28 (34\%) & \multirow[t]{2}{*}{.54} & $21(26 \%)$ & \multirow[t]{2}{*}{.81} \\
\hline Age $\geq 65$ y & $13(29 \%)$ & & $21(28 \%)$ & \\
\hline \multicolumn{5}{|l|}{ Insomnia } \\
\hline Age $<65$ y & 55 (67\%) & \multirow[t]{2}{*}{.13} & 48 (60\%) & \multirow[t]{2}{*}{.87} \\
\hline Age $\geq 65 y$ & 24 (53\%) & & $46(61 \%)$ & \\
\hline Hot flashes & & & & \\
\hline Age $<65$ y & $40(49 \%)$ & $<.001$ & $30(38 \%)$ & .009 \\
\hline Age $\geq 65$ y & $8(18 \%)$ & & $14(19 \%)$ & \\
\hline Dyspnea & & & & \\
\hline Age $<65$ y & $18(22 \%)$ & .38 & $14(18 \%)$ & .17 \\
\hline Age $\geq 65$ y & $13(29 \%)$ & & $20(27 \%)$ & \\
\hline Aching joints/a & & & & \\
\hline Age $<65$ y & $40(49 \%)$ & .15 & $22(28 \%)$ & .005 \\
\hline Age $\geq 65$ y & $16(36 \%)$ & & $37(49 \%)$ & \\
\hline Aching muscle & & & & \\
\hline Age $<65$ y & $39(48 \%)$ & .19 & 25 (31\%) & .33 \\
\hline Age $\geq 65 y$ & $16(36 \%)$ & & 29 (39\%) & \\
\hline Peripheral neu & & & & \\
\hline Age $<65$ y & 35 (43\%) & 36 & $17(21 \%)$ & .06 \\
\hline Age $\geq 65$ y & 23 (51\%) & & $26(35 \%)$ & \\
\hline Edema limbs & & & & \\
\hline Age $<65$ y & $20(24 \%)$ & .99 & $18(23 \%)$ & .33 \\
\hline Age $\geq 65$ y & $11(24 \%)$ & & $22(29 \%)$ & \\
\hline Abdominal pai & & & & \\
\hline Age $<65$ y & $16(20 \%)$ & .38 & $16(20 \%)$ & .33 \\
\hline Age $\geq 65 y$ & $6(13 \%)$ & & $20(27 \%)$ & \\
\hline General pain & & & & \\
\hline Age $<65$ y & $39(48 \%)$ & .07 & 31 (39\%) & .87 \\
\hline Age $\geq 65 y$ & $14(31 \%)$ & & $30(40 \%)$ & \\
\hline Constipation & & & & \\
\hline Age $<65$ y & $39(48 \%)$ & .92 & $20(25 \%)$ & .19 \\
\hline Age $\geq 65$ y & $21(47 \%)$ & & $26(35 \%)$ & \\
\hline Diarrhea & & & & \\
\hline Age $<65$ y & $26(32 \%)$ & .49 & 44 (55\%) & .97 \\
\hline Age $\geq 65 y$ & 17 (38\%) & & $41(55 \%)$ & \\
\hline Nausea & & & & \\
\hline Age $<65$ y & 40 (49\%) & .23 & $23(29 \%)$ & .43 \\
\hline Age $\geq 65$ y & 17 (38\%) & & $26(35 \%)$ & \\
\hline Vomiting & & & & \\
\hline Age $<65$ y & $7(9 \%)$ & .64 & $10(13 \%)$ & .22 \\
\hline Age $\geq 65 y$ & $5(11 \%)$ & & $5(7 \%)$ & \\
\hline Mucositis oral & & & & \\
\hline Age $<65$ y & $26(32 \%)$ & .74 & 15 (19\%) & .99 \\
\hline Age $\geq 65 y$ & 13 (29\%) & & 14 (19\%) & \\
\hline Hospitalization & & & & \\
\hline Age $<65$ y & 19 (23\%) & .90 & $12(15 \%)$ & .17 \\
\hline Age $\geq 65$ y & 10 (22\%) & & $7(9 \%)$ & \\
\hline Dose reductior & & & & \\
\hline Age $<65$ y & 35 (42\%) & .08 & $21(26 \%)$ & .36 \\
\hline Age $\geq 65$ y & $12(27 \%)$ & & 25 (33\%) & \\
\hline Dose delay & & & & \\
\hline Age $<65$ y & 28 (34\%) & .41 & $8(10 \%)$ & .02 \\
\hline Age $\geq 65 y$ & $12(27 \%)$ & & $18(24 \%)$ & \\
\hline
\end{tabular}


TABLE 2. Continued

\begin{tabular}{|c|c|c|c|c|}
\hline Symptom & $\begin{array}{l}\text { Anthracycline-Based } \\
\text { (AC-T and AC-TC) }\end{array}$ & $P^{\mathrm{a}}$ & $\begin{array}{c}\text { Nonanthracycline-Based } \\
\text { (TC and TCH) }\end{array}$ & $P^{a}$ \\
\hline \multicolumn{5}{|c|}{ Early treatment discontinuation } \\
\hline Age $<65$ y & 17 (20\%) & .71 & $9(11 \%)$ & .55 \\
\hline Age $\geq 65 y$ & $8(18 \%)$ & & 11 (14\%) & \\
\hline
\end{tabular}

Abbreviations: AC-T, dose-dense doxorubicin and cyclophosphamide followed by paclitaxel; AC-TC, doxorubicin and cyclophosphamide plus paclitaxel and carboplatin; MSVS, moderate, severe, or very severe; TC, docetaxel and cyclophosphamide; TCH, docetaxel and carboplatin with anti-HER2 therapy.

$P$ values for categorical variables were based on the chi-square test for comparing percentages across age groups; $P$ values for continuous variables were based on the 2-sample Student $t$ test for comparing means across age groups.

${ }^{a}$ Bold type indicates statistical significance.

interference associated with hot flashes $(26 \%$ vs $9 \%$; $P=.006$ ), whereas a higher percentage of older women reported MSVS interference associated with abdominal pain $(13 \%$ vs $28 \% ; P=.02)$. For all other symptoms within the 2 regimen groups, there were no statistically significant differences noted between younger and older women.

\section{Adverse Events During Chemotherapy}

For all chemotherapy regimens combined (Table 1), there were no significant differences observed between older and younger patients with regard to hospitalization $(19 \%$ vs $12 \% ; P=.19)$, dose reduction ( $34 \%$ vs $31 \% ; P=.50)$, dose delay $(22 \%$ vs $25 \% ; P=.59)$, or early treatment discontinuation (16\% vs $16 \% ; P=.95)$. However, among women who received a non-anthracyclinebased regimen, younger women experienced fewer dose delays compared with older women $(10 \%$ vs $24 \%$; $P$ $=.02$ ) Among all participants combined, the primary reasons for dose reductions were peripheral neuropathy (34\%), neutropenic fever (13\%), anemia (5\%), and miscellaneous other $(48 \%)$; the primary reasons for early treatment discontinuation were peripheral neuropathy (28\%) and miscellaneous other (72\%); and the primary reasons for hospitalization were neutropenic fever $(28 \%)$ and miscellaneous other (72\%).

\section{DISCUSSION}

Over the past decade, there has been growing evidence from treatment trials that women aged $\geq 65$ years can be fit and otherwise well suited for a wide variety of chemotherapy regimens. Rather than using age as the sole determinant of chemotherapy use, there is strong evidence that a brief assessment of function, cognition, and social circumstances can provide essential information regarding suitability for chemotherapy in the older patient. ${ }^{9,10,25}$

In the current study, we reported that patient-reported symptom severity and symptom interference with daily activities were found to demonstrate little difference between older and younger patients for 17 symptoms associated with chemotherapy regimens commonly used in current clinical practice. Older and younger patients reported similar symptom severity regardless of whether the regimen was anthracycline-based or not. One exception was the side effect of hot flashes, which should have been expected to be a greater concern in younger women, especially those who were premenopausal or perimenopausal at the time of breast cancer diagnosis. The data from the current study support findings from other studies comparing older and younger women who were receiving treatment for breast cancer who similarly reported few significant differences with regard to symptom severity, ${ }^{26}$ with the exception of dyspnea (which was found to be less severe in older patients) ${ }^{29}$ and greater sleep impairment in patients aged $\geq 50$ years, ${ }^{28}$ although it should be noted that the chemotherapy regimens in these prior studies differed from the regimens used in the current study.

A strength of the current study was the collection of prospective data regarding 327 women who were receiving chemotherapy, approximately $43 \%$ of whom were aged $\geq 65$ years. We reported symptom severity as well as interference with activities of daily living. However, as we noted in our previous work, ${ }^{17}$ a limitation of the current study was that we collected patient-reported symptoms according to cycle length (every 2 or 3 weeks) within the time frame of "the past 7 days." As a consequence, brief symptom spikes that had abated from one week to the next may not have been apparent. We were unable to speculate as to whether this might have systematically biased our study results, but are unaware of data suggesting that the duration of symptom intensity within a 2 -week to 3 -week cycle can vary by age. We collected, on average, a similar number of total symptom reports in both age groups (see Supporting Table 1).

Separately, and more important, participants in the current study were deemed by their treating clinician to be appropriate candidates for chemotherapy, and 

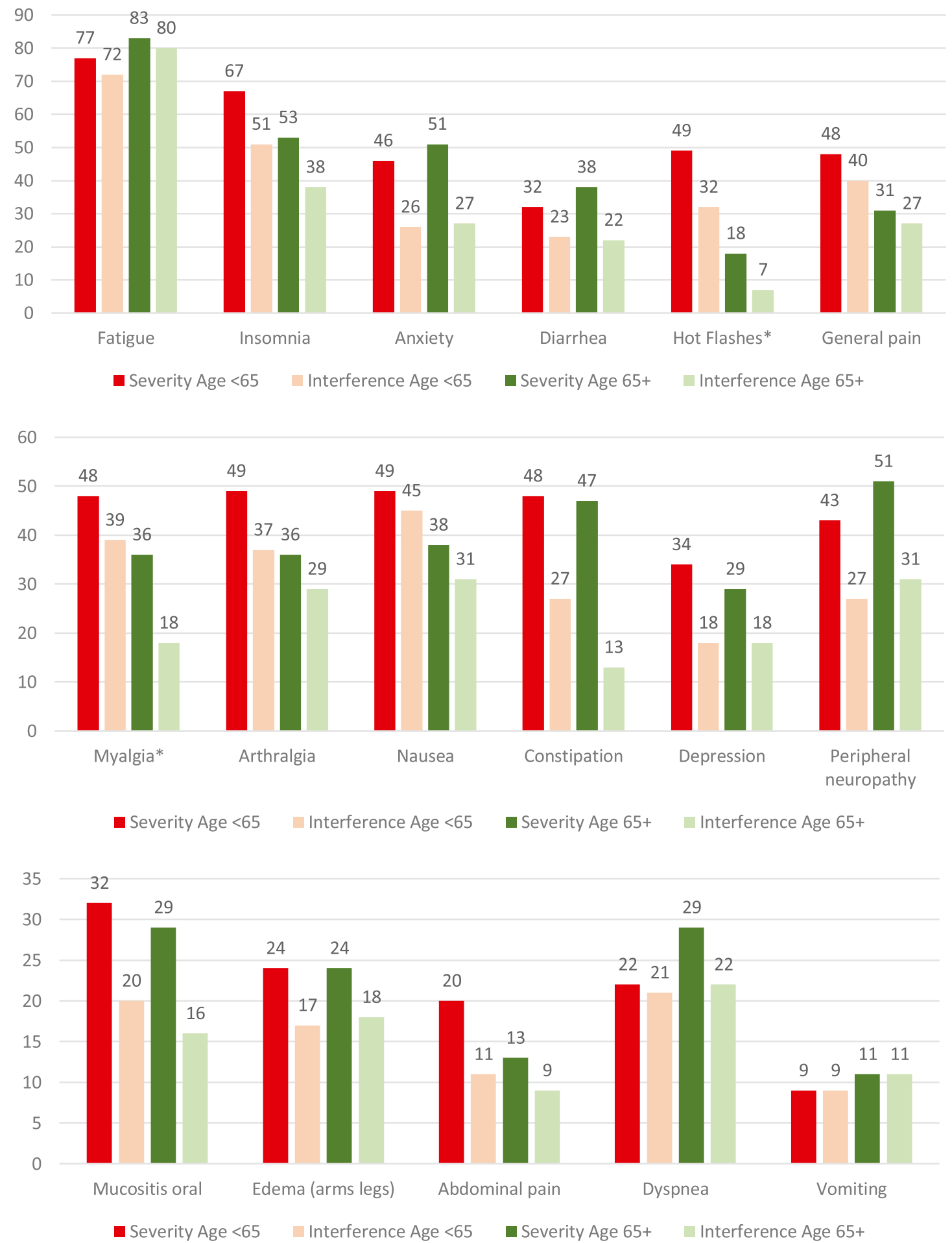

Figure 1. Anthracycline-based chemotherapy. Patient-reported moderate, severe, or very severe symptom severity and interference with daily activities (shown as percentage) for each symptom for younger (aged $<65$ years) versus older (aged $\geq 65$ years) patients. Asterisks represent significant differences.

provider bias regarding whether to offer chemotherapy to older patients or to offer specific regimens could not be addressed. Thus, the current study findings in older women may represent the experience of a particularly fit subgroup of patients who were deemed appropriate for chemotherapy. 

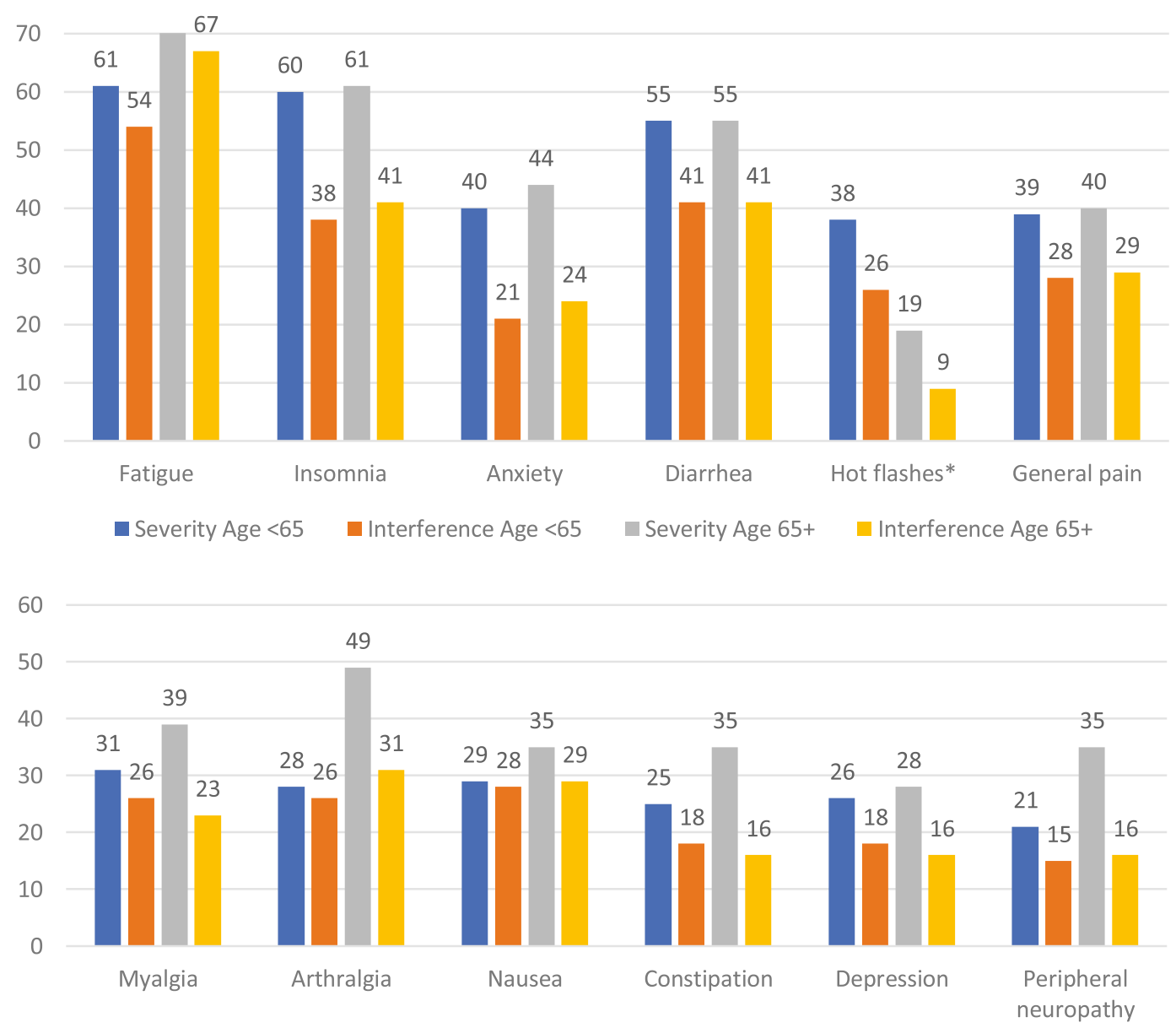

- Severity Age $<65 \square$ Interference Age $<65 \quad$ Severity Age 65+ $\quad$ Interference Age 65+

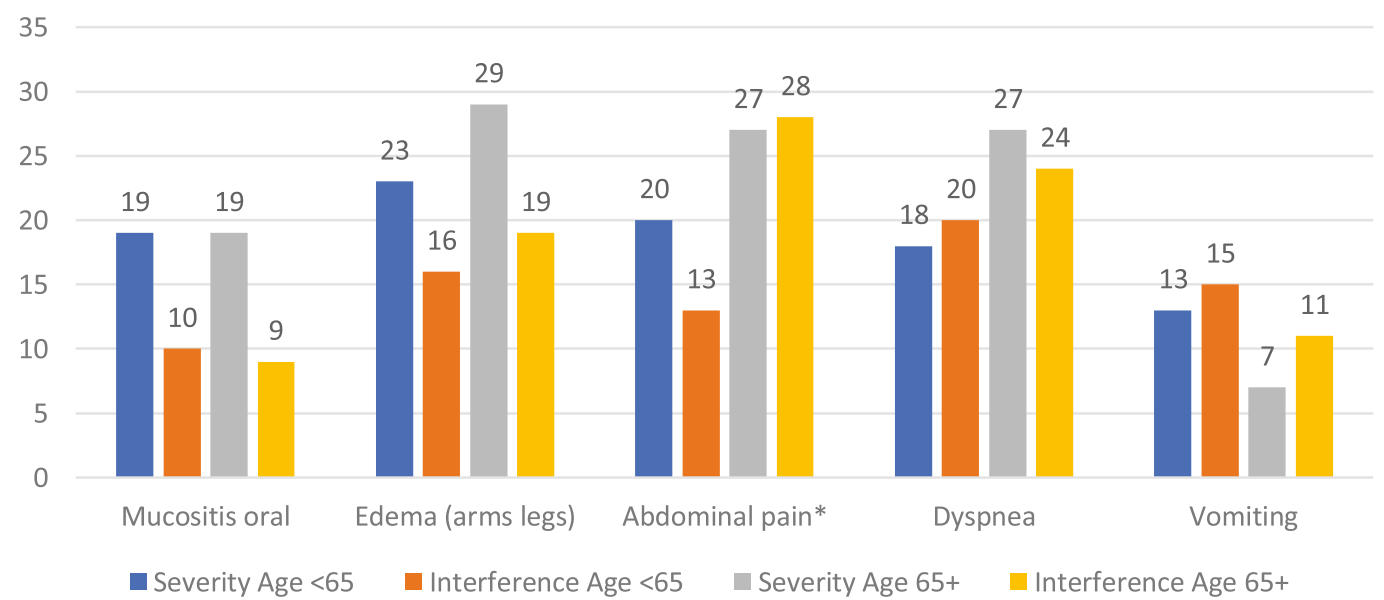

Figure 2. Non-anthracycline-based chemotherapy. Patient-reported moderate, severe, or very severe symptom severity and interference with daily activities (shown as percentage) for each symptom for younger (aged <65 years) versus older (aged $\geq 65$ years) patients. Asterisks represent significant differences.

Finally, we noted that all study participants were enrolled in a self-directed walking program. Very few patients who were identified by the research team as potential study participants were deemed inappropriate for a moderate exercise study by their treating oncologist. In general, both older and younger patients who were deemed "fit" for 
TABLE 3. Patient-Reported Symptom Interference With Daily Activities (MSVS) of Anthracycline-Based and Nonanthracycline Chemotherapy Regimens in Younger Versus Older Patients (Shown as the Percentage)

\begin{tabular}{|c|c|c|c|c|}
\hline Symptom & $\begin{array}{l}\text { Anthracycline-Based (AC-T and } \\
\text { AC-TC) }\end{array}$ & $P^{\mathrm{a}}$ & Nonanthracycline (TC and $\mathrm{TCH})$ & $P^{\mathrm{a}}$ \\
\hline \multicolumn{5}{|c|}{ Fatigue, lack of energy } \\
\hline Age $<65$ y & $59(72 \%)$ & \multirow[t]{2}{*}{.32} & $43(54 \%)$ & \multirow[t]{2}{*}{.10} \\
\hline Age $\geq 65 y$ & $36(80 \%)$ & & $50(67 \%)$ & \\
\hline \multicolumn{5}{|l|}{ Anxiety } \\
\hline Age $<65$ y & $21(26 \%)$ & \multirow[t]{2}{*}{.90} & $17(21 \%)$ & \multirow[t]{2}{*}{.68} \\
\hline Age $\geq 65 y$ & $12(27 \%)$ & & $18(24 \%)$ & \\
\hline \multicolumn{5}{|l|}{ Depression } \\
\hline Age $<65 y$ & 15 (18\%) & \multirow[t]{2}{*}{.94} & $14(18 \%)$ & \multirow{2}{*}{.80} \\
\hline Age $\geq 65 y$ & $8(18 \%)$ & & $12(16 \%)$ & \\
\hline \multicolumn{5}{|l|}{ Insomnia } \\
\hline Age $<65 y$ & $42(51 \%)$ & \multirow[t]{2}{*}{.15} & $30(38 \%)$ & \multirow[t]{2}{*}{.63} \\
\hline Age $\geq 65 y$ & 17 (38\%) & & $31(41 \%)$ & \\
\hline \multicolumn{5}{|l|}{ Hot flashes } \\
\hline Age $<65$ y & $26(32 \%)$ & \multirow[t]{2}{*}{.001} & $21(26 \%)$ & \multirow[t]{2}{*}{.006} \\
\hline Age $\geq 65 y$ & $3(7 \%)$ & & 7 (9\%) & \\
\hline \multicolumn{5}{|l|}{ Dyspnea } \\
\hline Age $<65$ y & $16(20 \%)$ & \multirow[t]{2}{*}{.72} & $16(20 \%)$ & \multirow[t]{2}{*}{.55} \\
\hline Age $\geq 65 y$ & $10(22 \%)$ & & $18(24 \%)$ & \\
\hline \multicolumn{5}{|c|}{ Aching joints/arthralgia } \\
\hline Age $<65 y$ & $30(37 \%)$ & \multirow[t]{2}{*}{.38} & $21(26 \%)$ & \multirow[t]{2}{*}{.54} \\
\hline Age $\geq 65 y$ & $13(29 \%)$ & & $23(31 \%)$ & \\
\hline Aching muscle & & & & \\
\hline Age $<65$ y & $31(38 \%)$ & .02 & $21(26 \%)$ & .60 \\
\hline Age $\geq 65 y$ & $8(18 \%)$ & & $17(23 \%)$ & \\
\hline Peripheral nes & & & & \\
\hline Age $<65 y$ & $22(27 \%)$ & .61 & $12(15 \%)$ & .86 \\
\hline Age $\geq 65 y$ & $14(31 \%)$ & & $12(16 \%)$ & \\
\hline Edema limbs & & & & \\
\hline Age $<65 y$ & $14(17 \%)$ & .92 & $13(16 \%)$ & .69 \\
\hline Age $\geq 65 y$ & $8(18 \%)$ & & 14 (19\%) & \\
\hline Abdominal pa & & & & \\
\hline Age $<65$ y & $9(11 \%)$ & .71 & $10(13 \%)$ & .02 \\
\hline Age $\geq 65 y$ & $4(9 \%)$ & & $21(28 \%)$ & \\
\hline General pain & & & & \\
\hline Age $<65 y$ & $33(40 \%)$ & .20 & $22(28 \%)$ & .80 \\
\hline Age $\geq 65 y$ & $13(27 \%)$ & & 22 (29\%) & \\
\hline Constipation & & & & \\
\hline Age $<65$ y & $22(27 \%)$ & .08 & $14(18 \%)$ & .83 \\
\hline Age $\geq 65 y$ & $6(13 \%)$ & & 12 (16\%) & \\
\hline Diarrhea & & & & \\
\hline Age $<65$ y & $19(23 \%)$ & .90 & $33(41 \%)$ & .99 \\
\hline Age $\geq 65 y$ & $10(22 \%)$ & & $31(41 \%)$ & \\
\hline Nausea & & & & \\
\hline Age $<65$ y & $37(45 \%)$ & .12 & $22(28 \%)$ & .80 \\
\hline Age $\geq 65 y$ & $14(31 \%)$ & & $22(29 \%)$ & \\
\hline Vomiting & & & & \\
\hline Age $<65$ y & $7(9 \%)$ & .64 & $12(15 \%)$ & .40 \\
\hline Age $\geq 65 y$ & $5(11 \%)$ & & $8(11 \%)$ & \\
\hline Mucositis oral & & & & \\
\hline Age $<65$ y & $16(20 \%)$ & .58 & $8(10 \%)$ & .89 \\
\hline Age $\geq 65 y$ & $7(16 \%)$ & & $7(9 \%)$ & \\
\hline
\end{tabular}

Abbreviations: AC-T, dose-dense doxorubicin and cyclophosphamide followed by paclitaxel; AC-TC, doxorubicin and cyclophosphamide plus paclitaxel and carboplatin; MSVS, moderate, severe, or very severe; TC, docetaxel and cyclophosphamide; TCH, docetaxel and carboplatin with anti-HER2 therapy.

$P$ values for categorical variables were based on the chi-square test for comparing percentages across age groups; $P$ values for continuous variables were based on the 2-sample Student $t$ test for comparing means across age groups.

abold type indicates statistical significance.

chemotherapy were fit for self-directed walking. Symptom experience may have been moderated in women who engaged in walking during chemotherapy compared with those who did not engage in walking. We previously reported that engaging in moderate walking during chemotherapy is very challenging, even among women aged $<65$ years who were enrolled in our intervention studies. ${ }^{29}$

Although the women in the current study scored symptom interference as consistently lower than symptom severity, the high prevalence of moderate or higher 
symptom severity in both age groups underscores the importance of ongoing symptom monitoring in patients of all ages and communication regarding symptom management with the treatment team. ${ }^{30,31}$ It is perhaps easier for patients to communicate that a symptom is interfering with their daily activities rather than convey the absolute severity of a symptom, which may explain why clinicians are reported to often underestimate actual symptom intensity. ${ }^{18}$

\section{Conclusions}

Women aged $<65$ years and those aged $\geq 65$ years who are undergoing chemotherapy for early breast cancer have reported similarly high levels of MSVS treatment-related symptoms. Overall, both older and younger women appeared to perceive symptom interference with activities of daily living as being less concerning than symptom severity. The findings of the current study confirm those of prior studies demonstrating that chemotherapy options need not be constrained by the chronological age of the patient.

\section{FUNDING SUPPORT}

Supported by the Breast Cancer Research Foundation (New York, NY), the Kay Yow Cancer Fund (Raleigh, NC), and the UNC Lineberger Comprehensive Cancer Center/University Cancer Research Fund (Chapel Hill, NC).

\section{CONFLICT OF INTEREST DISCLOSURES}

William A. Wood has received grants from Pfizer for work performed outside of the current study. Shlomit S. Shachar has received personal fees and nonfinancial support for travel and lectures from Roche, Novartis, and Pfizer for work performed outside of the current study. Gretchen G. Kimmick has received fees for accrual from the University of North Carolina at Chapel Hill (subcontract) for work performed as part of the current study and has received grants from and acted as a paid consultant for Pfizer; has received grants from Novartis; has acted as a paid member of the scientific advisory board for Boehringer Ingelheim; has acted as a paid member of the scientific advisory board for and received honoraria from Eisai; has acted as a paid member of the scientific advisory board for and received consulting fees from Genomic Health; has acted as a paid member of the scientific advisory board for Agendia; has acted as a paid consultant for AstraZeneca; has received royalties from UpToDate and Springer; has received fees for a dinner meeting from Foundation Medicine; and has received research funding from Bionovo, Puma, and Roche for work performed outside of the current study. The other authors made no disclosures.

\section{AUTHOR CONTRIBUTIONS}

Kirsten A. Nyrop: Primary author, writing-original draft, writing-review and editing, conceptualization, and project administration. Allison $\mathbf{M}$. Deal: Statistical analysis, conceptualization, and oversight. Yi Tang Chen: Statistical analysis. Bryce B. Reeve: Editing article and critical appraisal of content. Ethan M. Basch: Editing article and critical appraisal of content. William A. Wood: Editing article and critical appraisal of content. Shlomit S. Shachar: Verifying methods, editing article, and critical appraisal of content. Lisa A. Carey: Editing article and critical appraisal of content. Katherine E. Reeder-Hayes: Editing article and critical appraisal of content. E. Claire Dees: Editing article and critical appraisal of content. Trevor A. Jolly: Editing article and critical appraisal of content. Gretchen G. Kimmick: Editing article and critical appraisal of content. Meghan
S. Karuturi: Editing article and critical appraisal of content. Raquel E. Reinbolt: Editing article and critical appraisal of content. JoEllen C. Speca: Editing article and critical appraisal of content. Jordan T. Lee: Data collection, editing article, and critical appraisal of content. Addison Brenizer: Data collection, editing article and critical appraisal of content. Hyman B. Muss: Senior author, writing-original draft, writing-review and editing, verifying methods, and critical appraisal of content.

\section{REFERENCES}

1. Surveillance, Epidemiology, and End Results (SEER) Program. Breast cancer: SEER Fact Sheets. Published 2018. Accessed December 10, 2018. http://seer.cancer.gov/statfacts/html/breast/html

2. Barginear MF, Muss H, Kimmick G, et al. Breast cancer and aging: results of the U13 conference breast cancer panel. Breast Cancer Res Treat. 2014;146:1-6.

3. Freedman RA, Foster JC, Seisler DK, et al. Accrual of older patients with breast cancer to Alliance systemic therapy trials over time: protocol A151527. J Clin Oncol. 2017;35:421-431.

4. Gwede CK, Johnson DJ, Daniels SS, Trotti A. Assessment of toxicity in cooperative oncology clinical trials: the long and short of it. J Oncol Manag. 2002;11:15-21.

5. National Cancer Institute. Common Terminology Criteria for Adverse Events (CTCAE) v.5. Published 2017. Accessed October 23, 2017. https://evs.nci.nih.gov/ftp1/CTCAE/CTCAE_4.03_2010-06-14_ QuickReference_5x7.pdf

6. Klepin HD, Pitcher BN, Ballman KV, et al. Comorbidity, chemotherapy toxicity, and outcomes among older women receiving adjuvant chemotherapy for breast cancer on a clinical trial: CALGB 49907 and CALGB 361004 (Alliance). J Oncol Pract. 2014;10:e285-e292.

7. Freedman RA, Pitcher B, Keating NL, et al. Cognitive function in older women with breast cancer treated with standard chemotherapy and capecitabine on Cancer and Leukemia Group B 49907. Breast Cancer Res Treat. 2013;139:607-616.

8. Taylor WC, Muss HB. Adjuvant chemotherapy of breast cancer in the older patient. Oncology. 2010;24:608-613.

9. Jolly TA, Williams GR, Bushan S, et al. Adjuvant treatment for older women with invasive breast cancer. Womens Health (Lond). 2016;12:129-145; quiz 145-146.

10. Karuturi M, VanderWalde N, Muss H. Approach and management of breast cancer in the elderly. Clin Geriatr Med. 2016;32:133-153.

11. Sammons S, Sedrak MS, Kimmick GG. The evolving complexity of treating hormone receptor-positive, human epidermal growth factor receptor-2 (HER2)-negative breast cancer: special considerations in older breast cancer patients-Part I: early-stage disease. Drugs Aging. 2020;37:331-348.

12. Basch E, Pugh SL, Dueck AC, et al. Feasibility of patient reporting of symptomatic adverse events via the patient-reported outcomes version of the Common Terminology Criteria for Adverse Events (PROCTCAE) in a chemoradiotherapy cooperative group multicenter clinical trial. Int J Radiat Oncol Biol Phys. 2017;98:409-418.

13. Reeve BB, Mitchell SA, Dueck AC, et al. Recommended patient-reported core set of symptoms to measure in adult cancer treatment trials. J Natl Cancer Inst. 2014;106:dju129.

14. Judson TJ, Bennett AV, Rogak LJ, et al. Feasibility of long-term patient self-reporting of toxicities from home via the Internet during routine chemotherapy. J Clin Oncol. 2013;31:2580-2585.

15. Stover AM, Basch EM. Implementation of symptom questionnaires into oncology workflow. J Oncol Pract. 2016;12:859-862.

16. Basch E. Missing patients' symptoms in cancer care delivery-the importance of patient-reported outcomes. JAMA Oncol. 2016;2:433-434.

17. Nyrop KA, Deal AM, Shachar SS, et al. Patient-reported toxicities during chemotherapy regimens in current clinical practice for early breast cancer. Oncologist. 2019;24:762-771.

18. Nyrop KA, Deal AM, Reeve BB. Congruence of patient- and clinician-reported toxicity in women receiving chemotherapy for early breast cancer. Cancer. 2020;126:3084-3093.

19. Smith BD, Jiang J, McLaughlin SS, et al. Improvement in breast cancer outcomes over time: are older women missing out? J Clin Oncol. 2011;29:4647-4653.

20. Amin MB, Edge S, Greene F, eds. AJCC Cancer Staging Manual. 8th edn. Chicago IL: Springer; 2017. 
21. Nyrop KA, Deal AM, Reeder-Hayes KE, et al. Patient-reported and clinician-reported chemotherapy-induced peripheral neuropathy in patients with early breast cancer: current clinical practice. Cancer. 2019;125:2945-2954.

22. Gradishar WJ, Anderson BO, Balassanian R, et al. Breast Cancer, Version 4.2017, NCCN Clinical Practice Guidelines in Oncology. J Natl Compr Canc Netw. 2018;16:310-320.

23. Basch E, Reeve BB, Mitchell SA, et al. Development of the National Cancer Institute's patient-reported outcomes version of the Common Terminology Criteria for Adverse Events (PRO-CTCAE). J Natl Cancer Inst. 2014;106:dju244.

24. Dueck AC, Mendoza TR, Mitchell SA, et al; National Cancer Institute PRO-CTCAE Study Group. Validity and reliability of the US National Cancer Institute's Patient-Reported Outcomes version of the Common Terminology Criteria for Adverse Events (PRO-CTCAE). JAMA Oncol. 2015;1:1051-1059.

25. Mandelblatt JS, Cai L, Luta G, et al. Frailty and long-term mortality of older breast cancer patients: CALGB 369901 (Alliance). Breast Cancer Res Treat. 2017;164:107-117.

26. Leinert E, Singer S, Janni W, et al. The impact of age on quality of life in breast cancer patients receiving adjuvant chemotherapy: a comparative analysis from the prospective multicenter randomized ADEBAR trial. Clin Breast Cancer. 2017;17:100-106.

27. Browall MM, Ahlberg KM, Persson LO, Karlsson PO, Danielson EB. The impact of age on Health-Related Quality of Life (HRQoL) and symptoms among postmenopausal women with breast cancer receiving adjuvant chemotherapy. Acta Oncol. 2008;47:207-215.

28. Enderlin CA, Coleman EA, Cole C, Richards KC, Hutchins LF, Sherman AC. Sleep across chemotherapy treatment: a growing concern for women older than 50 with breast cancer. Oncol Nurs Forum. 2010;37:461-A3.

29. Nyrop KA, Deal AM, Choi SK, et al. Measuring and understanding adherence in a home-based exercise intervention during chemotherapy for early breast cancer. Breast Cancer Res Treat. 2018;168:43-55.

30. Mandelblatt JS, Makgoeng SB, Luta G, et al. A planned, prospective comparison of short-term quality of life outcomes among older patients with breast cancer treated with standard chemotherapy in a randomized clinical trial vs. an observational study: CALGB \#49907 and \#369901. J Geriatr Oncol. 2013;4:353-361.

31. Yeom HE, Heidrich SM. Relationships between three beliefs as barriers to symptom management and quality of life in older breast cancer survivors. Oncol Nurs Forum. 2013;40:E108-E118. 